\title{
BIODIVERSIDADE E PROPRIEDADE INTELECTUAL: UMA PERSPECTIVA SOBRE APROPRIAÇÃO DO CONHECIMENTO DOS POVOS TRADICIONAIS ${ }^{1}$
}

\author{
Jerônimo Siqueira Tybusch ${ }^{2}$ \\ Letícia Thomasi Jahnke ${ }^{3}$ \\ Thiago Luiz Rigon de Araujo ${ }^{4}$
}

\section{RESUMO}

O presente artigo tem por objetivo abordar além da questão da Propriedade Intelectual e sua definição e seu regime, mas também busca um enfoque especial no campo da biodiversidade, que gera perspectivas de expansão econômica dos países desenvolvidos do norte, outorgados pelos interesses das grandes empresas transnacionais, a partir da exploração e apropriação dos recursos naturais prospectados na vasta biodiversidade dos países pobres e subdesenvolvidos, prática a qual pode ser denominada biopirataria. A referida apropriação dos conhecimentos dos povos tradicionais desses desfavorecidos países, além de gerar um grande problema socioeconômico, em especial no caso da América Latina, o que resulta em um entrave do seu crescimento econômico, e ameaça também os povos tradicionais em suas culturas, já que as mesmas deveriam ser protegidas pois são vitais para o futuro, desenvolvimento e bem estar social desses povos.

\section{ASPECTOS INTRODUTÓRIOS}

O presente ensaio aborda a necessidade de formação de espaços de atuação que objetivem ações emancipatórias no campo de atuação de um Direito da Sociobiodiversidade. Dessa forma, a instrumentalidade da técnica jurídico-ambiental nos países extremamente biodiversos desse continente deve possibilitar a construção de espaços de ação onde operem decisões que transcendam a simples valorização monetária dos bens naturais e a racionalidade do Homo Oeconomicus, típica da tradicional "Propriedade intelectual" calcada na apropriação do conhecimenteo, e possam também considerar as diferentes dimensões que compõem o conceito de

\footnotetext{
${ }^{1} \mathrm{O}$ presente artigo é fruto de investigações do Grupo de Pesquisa em Direito da Sociobiodiversidade e do projeto "Justiça Ambiental em Redes Colaborativas: e-democracy e Ecologia Política na Sociedade Informacional Latino-Americana" que recebe auxílio financeiro do CNPq - Edital Universal - 2011; registrado no Gabinete de Projetos do Centro de Ciências Sociais e Humanas da Universidade Federal de Santa Maria.

${ }^{2}$ Professor Adjunto do Departamento de Direito da Universidade Federal de Santa Maria - UFSM. Doutor pela Universidade Federal de Santa Catarina - UFSC. Mestre em Direito Público pela Universidade do Vale do Rio dos Sinos - UNISINOS. Graduado em Direito pela Universidade de Santa Cruz do Sul - UNISC. Coordenador do Projeto "Justiça Ambiental em Redes Colaborativas: e-democracy e Ecologia Política na Sociedade Informacional Latino-Americana" que recebe auxílio financeiro do CNPq - Edital Universal - 2011 Vice-Líder e Pesquisador do Grupo de Pesquisa em Direito da Sociobiodiversidade - GPDS/UFSM. E-mail: jeronimotybusch@ufsm.br; jeronimotybusch@gmail.com . Lattes: http://lattes.cnpq.br/6477064173761427

${ }^{3}$ Mestranda do Programa de Pós-Graduação em Direito, pela Universidade Regional Integrada do Alto Uruguai e das Missões (URI). Membro integrante do Grupo de Pesquisa em Direito da Sociobiodiversidade da Universidade Federal de Santa Maria. E-mail: leticia.thomasi@ hotmail.com

${ }^{4}$ Mestrando do Programa de Pós-Graduação em Direito, pela Universidade Regional Integrada do Alto Uruguai e das Missões (URI). Membro integrante do Grupo de Pesquisa em Direito da Sociobiodiversidade da Universidade Federal de Santa Maria. E-mail: rigondearaujo@gmail.com
} 
biodiversidade. Em outras palavras, o campo reflexivo da Ecologia Política e da construção de um Direito da Sociobiodiversidade pode incentivar a percepção de um Direito do Ambiente de raiz emancipatória para os países Latino-Americanos.

$\mathrm{Na}$ metodologia, utiliza-se a pesquisa bibliográfica e documental como procedimento para a produção de fichamentos e resumos estendidos, como técnica de pesquisa para posterior elaboração do presente artigo. A abordagem e teoria de base utilizados são a perspectiva sistêmico-complexa ${ }^{5}$ na qual, a comunicação de diversas áreas do saber como direito, ecologia e sustentabilidade são aplicadas para a resolução de questões complexas.

\title{
PROPRIEDADE INTELECTUAL E APROPRIAÇÃO DO CONHECIMENTO
}

Inicialmente, é importante fazer um delineamento prévio acerca da terminologia de Propriedade Intelectual, principalmente a utilizada pela Organização Mundial de Propriedade Intelectual (OMPI) em seu handbook sobre a questão da propriedade intelectual, preconiza que constituem propriedade intelectual as invenções, obras literárias e artísticas, nomes, imagens, símbolos, desenhos e modelos utilizados pelo comércio. É dizer, de modo geral, que a propriedade intelectual é um instituto legal que visa salvaguardar os criadores e produtores de bens intelectuais e serviços os direitos relativos a comercialização e demais recompensas por um determinado lapso de tempo, sejam essas criações nos domínios industrial, literário, artístico e científico.

Esses aclamados direitos sobre a propriedade intelectual, na sábia lição de Luiz Otávio Pimentel e Welber Barral, podem definir-se como:

“...os instrumentos que permitem uma posição jurídica(titularidade) e
uma posição econômica(exclusividade). A proteção jurídica tende a
garantir, ao seu titular, a recuperação de investimentos na pesquisa e
desenvolvimento (P\&D) tecnológico, que podem ser públicos ou
privados, diretos ou indiretos. Garante também uma posição

\begin{abstract}
${ }^{5}$ Em pesquisas desse gênero, evidencia-se a importância da matriz teórica como possibilidade de substituir o paradigma exclusivamente cartesiano, que ao tratar do processo de conhecimento como um fenômeno cognitivo em que se dá uma oposição ou mesmo distanciamento entre sujeito e objeto, provocaram um desenvolvimento social de visão fragmentada, com tendência ao isolamento humano e degradação ambiental; por uma nova perspectiva paradigmática de concepção pragmático-sistêmica, que eleva a condição humana e o meio ambiente ao mesmo patamar, de forma complexa, onde o fenômeno cognitivo é visto através de uma diferenciação funcional sistema-meio, e em que pese passar a considerarse o objeto e o sujeito inseparáveis, graças ao reconhecimento desse intercâmbio pela mediação da comunicação como pressuposto de contribuir ao desenvolvimento democrático da atual problemática ambiental, ou seja, alcançar uma comunicação da sociedade acerca da sociedade, no sentido de reconhecer-se, para estabelecer limites/possibilidades de gerar melhoria da qualidade de vida e desenvolvimento sustentável a todos (Capra, 2000, p.42).
\end{abstract}


III SEMINÁRII ECDLOGIA

POLÍTICA

E DIREITD NA AMÉRICA LATINA

econômica privilegiada e lícita nos mercados regionais ou nacional, para uma empresa em concorrência com outra, ao permitir a exclusividade de processo industrial, de comercialização de um produto ou serviço, de seu signo distintivo, de obra literária, artística ou científica. (BARRAL \& PIMENTEL, 2006, p.12)

Fica notável a constatação da repercussão econômica desse instituto de proteção na atividade empresarial e demais aspectos de desenvolvimento econômico em escala mundial, em especial nas relações internacionais, já que igualmente notória é a disputa desigual entre os países subdesenvolvidos do sul e os países desenvolvidos do norte, especificamente o continente europeu e os Estados Unidos da América. Outrossim, deve-se levar em conta o fator descrito anteriormente como uma injustiça, já que a existência desses Estados mais ou menos desenvolvidos e Estados já desenvolvidos, e de mega-empresas com mais capitais acumulados que o PIB de muitos países, manter esse regime jurídico de Propriedade Intelectual, cabalmente levaria a garantir a criação da tecnologia, artes e literatura e ciências a poucos centros de excelência de produção. (BARRAL \& PIMENTEL, 2006, p. 16)

Desta forma, também pode-se evidenciar que a apropriação do conhecimento de criação abrangidos pelo sistema de proteção a propriedade intelectual, torna-se mais acessível aos países desenvolvidos e suas grandes aglomerações comerciais frente aos países subdesenvolvidos e com limitação de investimentos para a pesquisa científica.

Segundo Letícia Borges da Silva (2006), frente a esse crescimento desmedido das grandes empresas e uma massificação social e cultural, fenômeno que vem ocorrendo constantemente, gerou uma maior preocupação no sentido de proteção de direitos coletivos, em especial no que tange o direito ambiental, de tal forma que esse direito foi tornando-se um dos principais pontos debatidos no âmbito mundial, desde a Conferência de Estocolmo, à Rio +20. Com isso, despertou-se uma atenção geral sobre a biodiversidade, não menos importante, tanto que se tornou tema central para a elaboração de um dos principais tratados internacionais, a Convenção Sobre Biodiversidade Biológica ou Biodiversidade(CDB).

Nesse liame, de modo que a biodiversidade tem tido como grandes aliados na sua proteção os povos tradicionais e povos indígenas, e, com a evolução da biotecnologia, os países desenvolvidos através de das grandes empresas, amparados por 
III SEMINÁRII ECDLOGIA

POLÍTICA

vultuosos investimentos, aproveitam-se da proteção a propriedade intelectual para se apropriar do conhecimento tradicional desse povos, ameaçando as suas identidades culturais e conhecimentos tradicionais.

Conhecimento o qual, segundo a OMPI, são de suma importância já que muitas dessas comunidades formam a sua visão holística do mundo através desses conhecimentos, o que é ignorado pela economia capitalista e o desenvolvimento econômico dos países, já que esses conhecimentos são o retorno do capital investido nas pesquisas das grandes empresas dos países do norte.

\section{BIODIVERSIDADE NO CONTEXTO DOS CONHECIMENTOS TRADICIONAIS}

Conforme visto acima, a biodiversidade e a apropriação de conhecimento tradicional dos povos tradicionais estão diretamente relacionadas em detrimento do regime de propriedade intelectual, já que são fonte de trabalho de muitas empresas que desenvolvem pesquisas intensas, com o fim de registrar suas patentes, o que tem causado alguns problemas jurídicos sociais e culturais.(SILVA, 2006, p. 299)

No que tange os problemas supracitados, é importante salientar que não somente em uma breve analise do contexto econômico, mas também o contexto sociocultural que vivem os países do sul, principalmente no caso dos latino-americanos. Deve-se isso ao fato que nesses países a concentração de diversidade cultural, pode de certa forma divergir do conceito clássico de propriedade intelectual para a proteção e a apropriação do conhecimento, já que a estabilidade social e o desenvolvimento econômico na América Latina podem e devem ser conquistados, mas desde que respeitada a sua imensa sociobiodiversidade. (SILVA, 2006, p. 301)

Para um melhor entendimento do presente estudo, é preciso ao menos tentar conceituar o termo biodiversidade, pois como entende certos autores, conceituar biodiversidade é tarefa de elevado grau de dificuldade, pois existe dissenso sobre seus elementos formadores. (BRUM \& MONTEIRO, 2006, p.135)

Em âmbito internacional, a CDB que fora firmada na ECO 92, defini biodiversidade como a " variabilidade entre organismos vivos de todas as origens, 


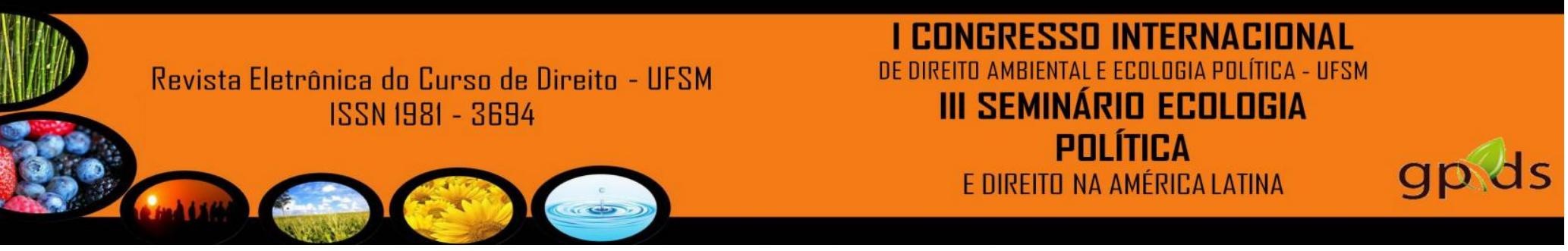

incluindo, inter alia, a terrestre, a marinha e outros ecossistemas aquáticos e os complexos ecológicos de que fazem parte. Inclui a diversidade interna às espécies, entre espécies e de ecossistemas".(CDB,2012)

Segundo a visão de Lévêque (1999, p.13), o termo biodiversidade é uma contração de diversidade biológica, e foi introduzido na década de 1980 pelos naturalistas que protestavam contra a destruição dos ambientes naturais e de suas espécies.

Mas, ainda na esteira desse pensamento de Lévêque,

\begin{abstract}
A biodiversidade não é um simples catálogo de genes, espécies ou ambientes. Ela deve ser percebida como um conjunto dinâmico e interativo entre os diferentes níveis da hierarquia biológica. Segundo as teorias atuais da evolução, é graças à existência de uma diversidade genética no seio das espécies que estas últimas podem se adaptar às mudanças do meio ambiente que sempre marcaram a história da Terra. Reciprocamente, a diversidade genética de uma espécie evolui em função do tempo, em resposta a essas mudanças do meio ambiente, bem como em razão das mutações. $\mathrm{O}$ mesmo ocorre com as comunidades vegetais e animais, que constituem os ecossistemas e que respondem por meio de mudanças qualitativas e quantitativas às flutuações do meio no qual elas vivem. Esta dinâmica dos sistemas biológicos e das condições ecológicas, às quais eles são confrontados, explica que as espécies evoluam e se diversifiquem e que os ecossistemas hospedam floras e faunas mais ou menos ricas, em virtude de sua história (1999, p.18).
\end{abstract}

Ainda nesse viés, é imperioso ressaltar a sábia lição de Vandana Shiva, uma lutadora em prol dos direitos das comunidades tradicionais:

A biodiversidade, a diversidade de formas de vida - plantas, animais, microorganismos -, é a base ecológica da vida. Também é o "capital natural" de dois terços da humanidade que depende da biodiversidade enquanto meio de produção - na agricultura, pesca, cuidados de saúde, e na produção de utensílios. Essa base de sobrevivência dos pobres é agora considerada como "matéria prima" para negócios e indústrias globais, porque, por um lado, as antigas tecnologias químicas já estão a falhar, tanto na agricultura como na saúde, e, por outro lado, a acumulação continuada de capital está a conduzir o lançamento de novas tecnologias, como a biotenologia, para o aumento de controle sobre os mercados e os recursos. (SHIVA, 2005, p.319)

Esse interesse pela biodiversidade e a sua apropriação pode ser motivado para fins econômicos como na agricultura, matérias primas para a indústria, medicamentos e uma crescente valorização no domínio das biotecnologias. Em termos ecológicos, sua motivação se dá porque é indispensável para manter os processos de evolução do mundo vivo. A biodiversidade possui um papel de regulação no equilíbrio físico-químicos da biosfera, contribui para a fertilidade do solo e sua proteção, bem como regula o ciclo hidrológico. Já quando se fala em termos éticos e patrimoniais, o homem tem o dever moral de não eliminar outras 


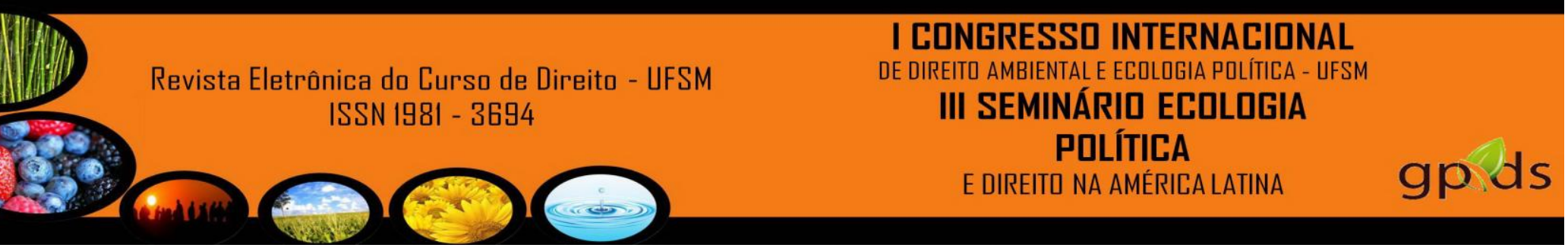

formas de vida, e o dever de transmitir as gerações futuras o que recebemos da natureza. (LÉVÊQUE, 1999, p.16)

\section{APROPRIAÇÃO DE CONHECIMENTOS TRADICIONAIS, BIOPIRATARIA E BIOPROSPECÇÃO}

É pratica comum o discurso que os países desenvolvidos afirmam que a proteção à biodiversidade se dará apenas através dos meios proteção dos organismos internacionais, embora esse discurso em grande parte do tempo, seja comprometido com o interesse de das grandes empresas transnacionais. (BRUM \& MONTEIRO, p.139)

$\mathrm{Na}$ atualidade, alguns autores de renome internacional, como Vandana Shiva, consideram essa ofensiva sistemática com requintes colonialistas dos países ricos do norte sobre a biodiversidade biológica dos países pobres, como uma nova forma de imperialismo, em especial no caso das industrias farmacêuticas dos países desenvolvidos que exploram a biodiversidade dos países subdesenvolvidos.

No entanto, mesmo que esses recursos extraídos na biodiversidade provenham dos países do Sul, estes têm que pagar os chamados "royalties" para explorar determinadas substancias ou processos patenteado no exterior, num cruel processo de apropriação dos conhecimentos das populações tradicionais.

De acordo com Vandana Shiva:

Dos 120 princípios ativos atualmente isolados na medicina moderna, $75 \%$ têm utilidades que foram identificadas pelos sistemas tradicionais. Menos de doze são sintetizados por modificações químicas simples; o resto é extraído diretamente de plantas e depois purificado. Diz-se que o uso do conhecimento tradicional aumenta a eficiência de reconhecer as propriedades medicinais de plantas em mais de 400\%. (SHIVA, 2005, p. 101)

Destarte, os lucros que são gerados a partir da exploração desse patrimônio genético, por óbvio, que não revertem aos povos detentores dessa riqueza. Isso é consequiência principalmente das negociações entabuladas a partir da Organização Mundial do Comércio (OMC), que estabeleceu a formação de um regime único de propriedade intelectual sobre as biotecnologias, em especial, sobre as invenções a partir da biodiversidade e dos conhecimentos tradicionais e ela associados.

\section{DIGRESSÕES FINAIS}




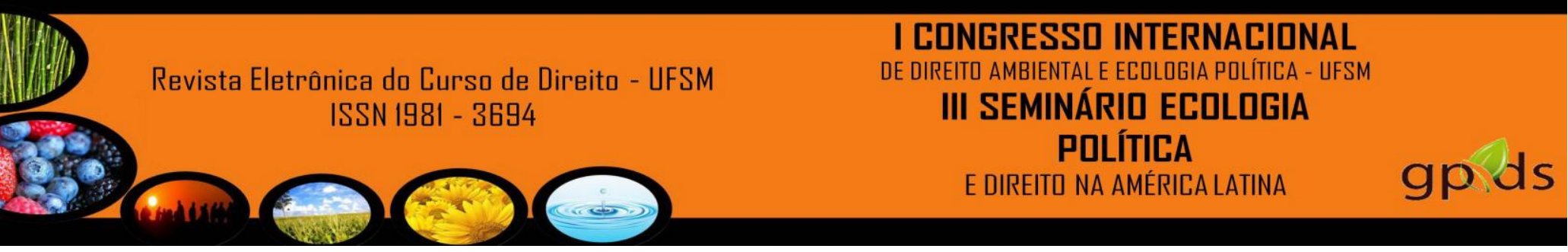

colocados múltiplos modos de viver e construir a realidade. Ressalta-se, porém, que isto não significa estar conformado com a desigualdade, mas o reconhecimento da sua dimensão para estabelecer um diálogo democrático na direção de um senso comum em defesa de todas as formas de vida, o qual parta das diferenças para poder superar as iniqüidades.

\section{REFERÊNCIAS}

BARRAL, Welber \& PIMENTAL, Luiz Otavio (Organizadores). Propriedade Intelectual e Desenvolvimento. Florianópolis, Fundação Boiteux, 2006.

BRUM, Fabiano Prado de; MONTEIRO, Christine Schor Monteiro. Propriedade Intelectual sobre a Biodiversidade e os conhecimentos tradicionais no Brasil: Biopirataria, Neocolonialismo e a proteção ao meio Ambiente In: PIMENTEL, Luiz Otávio; BOFF, Salete Oro; DEL'OLMO, Florisbal de Souza. Propriedade Intelectual: Gestão do conhecimento, inovação tecnológico no agronegócio e cidadania. Florianópolis: Fundação Boitex, 2008. 242p.

CAPRA, Fritjof. A Teia da vida. São Paulo: Cultrix, 2000.

CDB. Convenção de Diversidade biológica. Disponível em http://www.biodiv.org. Acesso em agosto de 2012.

LÉVÊQUE, Christian. A Biodiversidade. Tradução: Valdo Memelstein. Bauru, SP: EDUSC, 1999.

OMPI-WIPO Intellectual Property Handbook. Disponível em www.wipo.int/export/sites/www/freepublications/es/tk/920/wipo_pub_920.pdf. Acesso em Julho de 2012.

ONU - CEPAL. Análise Ambiental e de Sustentabilidade do Estado do Amazonas. Santiago - Chile: Nações Unidas, 2007.

Propiedad Intelectual y Recursos Genéticos, Conocimientos Tradicionales y Expresiones Culturales Tradicionales/Folclore. Disponível em http://www.wipo.int/export/sites/www/freepublications/es/tk/920/wipo_pub_920.pdf. Acesso em Julho de 2012.

SARAGOUSSI, Muriel. Direito de acesso à proteção e uso da biodiversidade. In: BORN, Rubens Harry (coord.). Diálogos entre as esferas global e local: contribuições de organizações não-governamentais e movimentos sociais brasileiros para a sustentabilidade, equidade e democracia planetária. São Paulo: Editora Fundação Peirópolis, 2002. 


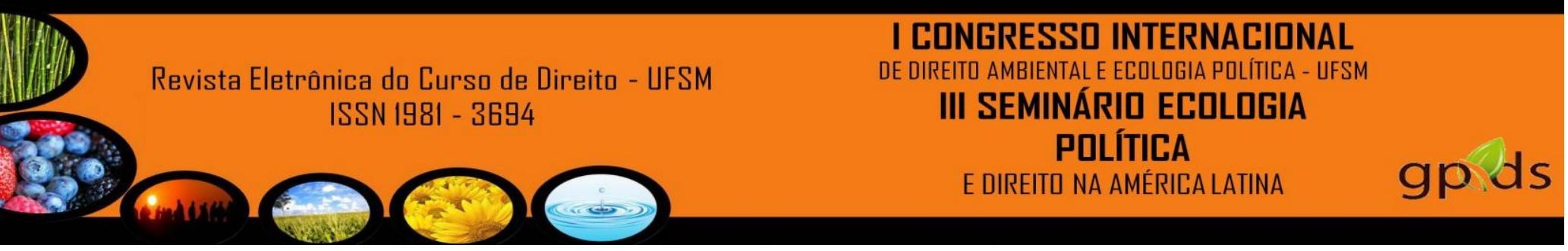

SHIVA, Vandana. Biopirataria: a pilhagem da natureza e do conhecimento. Trad. De Laura Cardellini B. de Oliveira. Petrópolis, RJ: Vozes, 2001.

Monoculturas da Mente: perspectivas da biodiversidade e da biotecnologia. Tradução: Dinah de Abreu Azevedo. São Paulo: Gaia, 2003.

Biodiversidade, Direitos de Propriedade Intelectual e Globalização. In Boaventura de Sousa Santos (org.). Semear outras soluções: os caminhos da biodiversidade e dos conhecimentos rivais. Rio de Janeiro: Civilização Brasileira, 2005 .

SILVA, Letícia Borges. É possível negociar a Biodiversidade? Conhecimentos Tradicionais, Propriedade Intelectual e Biopirataria. In: BARRAL, Welber e PIMENTEL, Luiz Otávio(orgs). Propriedade Intelectual e Desenvolvimento. Florianópolis: Fundação Boitex, 2006, pp. 299-328

VIEIRA, Vinícius Garcia. Direito da Biodiversidade e América Latina: A questão da Propriedade Intelectual. Ijuí: Editora Unijuí, 2012. 